\title{
Potato Peel as a Sustainable Resource of Natural Antioxidants for the Food Industry
}

\author{
Urszula Samotyja ${ }^{1}$ (iD
}

Received: 27 September 2018 / Accepted: 8 March 2019 /

Published online: 8 April 2019

(C) The Author(s) 2019

\begin{abstract}
Upgrading of food processing residues is currently a topic of global interest as scientists and industries have focused on using natural sources of antioxidants as an alternative to synthetic ones. The aim of the present work was to assess the potential of potato peel extracts of cultivars Gala and Jazzy in $96 \%$ ethanol, $80 \%$ ethanol and water by using antioxidant assays as well as model systems that contained food lipids. Extracts in $96 \%$ ethanol contained the highest amount of total phenolics (40.5 and $28.4 \mathrm{mg} / \mathrm{g}$ of dry weight) and showed the highest antiradical, reducing and iron-chelating potential, followed by extracts in $80 \%$ ethanol. The order of the extracts' activity in $\beta$-carotene bleaching assay was strongly concentration-dependent. Potato peel extracts showed high efficiency in retarding oxidation of rapeseed oil, where they performed better than butylated hydroxyanisole (BHA) and butylated hydroxytoluene (BHT). They also delayed conjugated diene and volatile formation in sunflower oil. Compounds of potato peel extracts act via several mechanisms, assuring long-term protection of food lipids. They are a promising source of antioxidants that should be chosen carefully for a given medium in order to be stabilized and to obtain optimal results. The manner of potato peel valorization proposed here is in line with the global challenge to reduce food production waste residues and also gives an opportunity to extend the shelf life of food.
\end{abstract}

Keywords Natural antioxidants · Potato peel $\cdot$ Shelf life $\cdot$ Sustainable production · Waste residues
Abbreviations
GE96 Gala extract in $96 \%$ ethanol
GE80 Gala extract in $80 \%$ ethanol
GW Gala water extract
JE96 Jazzy extract in $96 \%$ ethanol

Urszula Samotyja

urszula.samotyja@ue.poznan.pl

1 Department of Food Commodity Science, Faculty of Commodity Science, Poznań University of Economics and Business, al. Niepodległości 10, 61-875 Poznań, Poland 
JE80 Jazzy extract in $80 \%$ ethanol

JW Jazzy water extract

\section{Introduction}

Global intensification of food production has led to the generation of large quantities of food waste residues. With the current food economy and the future state of global natural resources and quality of the environment at stake, there has been a worldwide trend to implement the idea of sustainable development that puts emphasis on waste management. In order to reduce the mass of agro-industrial wastes, international organizations such as the United Nations and current legislation throughout the world have begun to strongly encourage the food industry to find new end uses for residues (European Union 2012; United Nations 2015; RedCorn et al. 2018).

The residues of fruit and vegetable industrial processing have been widely used for animal feed or as a source of energy, but it is believed that still too few residues are used in other applications e.g., in the food industry. The high nutritional and healthpromoting value and presence of active compounds such as antioxidants should favour this area of re-use or recovery (Kowalska et al. 2017).

Potatoes are one of the most commonly consumed crops in the world, which is connected with their impact on residue generation. The disposal of this waste poses a challenge. Potato peels constitute a major waste of potato processing that ranges from 15 to $40 \%$ of the initial product's mass; therefore, their valorization should be of interest to the food industry (Akyol et al. 2016; Gebrechristos and Chen 2018).

The periderm (skin) of the potato provides a protective layer for the potato tuber against phytopathogens and therefore contains numerous secondary metabolites, including phenolic compounds (Ezekiel et al. 2013; Huang et al. 2017). Phenolic antioxidants such as hydroxycinnamic and hydroxybenzoic acid derivatives and flavonoids have been found in the extracts of potato peel (Al-Weshahy and Rao 2009; Deußer et al. 2012). In accordance with the growing antipathy of consumers towards synthetic food additives, potato peels seem to constitute a potential source of natural antioxidants that can be used in the food industry (Carocho et al. 2018). Natural antioxidants have been the focus of scientists and food business operators' for many years. These compounds show similar or even higher potential than their synthetic counterparts, which makes them an attractive alternative to artificial agents (Sielicka and Małecka 2016; Özkan and Özcan 2017). The ubiquity of their occurrence in plants, as well as the great number of active compounds, creates the potential for extending the list of antioxidants feasible to use in food. Although the method of obtaining a given chemical does not prejudge its toxicity, synthetic compounds are disliked by consumers. In contrast to synthetic food additives, which are regarded as 'unhealthy' and provoke controversy, natural compounds are better perceived by consumers. Producers who are aware of consumers' attitudes avoid using them in food, replacing synthetic antioxidants with widely accepted compounds of natural origin (Carocho et al. 2018).

The recovery of natural antioxidants from plant material residues such as pomaces, kernels, skins and peels in order to extend the shelf life of lipid-containing foods is in line with sustainable management policy and consumers' expectations. 
The properties of potato peel extracts have been tested in in vitro antioxidant assays, but the data remain scarce and concern only selected cultivars out of over 300 described so far (AHDP Potatoes 2018). Moreover, still too few studies have been conducted on the potato peel's effectiveness in lipid matrices in the context of selective effect of antioxidants in different media and differentiated activity towards primary and secondary oxidation products (Frankel 2007). With possible new applications for potato peels such as in innovative food products or as a source of natural antioxidants used to stabilize food lipids, recognizing the factors influencing their properties is a key issue to be tackled. More studies are necessary in order to understand the mechanisms that determine the antioxidant power of potato peel extracts in order to effectively use their potential.

The aim of the present work was to assess the potential of six potato peel extracts by using antioxidant assays as well as model systems that contained food lipids.

\section{Materials and Methods}

\section{Materials and Reagents}

Samples of two cultivars of potato (Solanum tuberosum), Gala (G) and Jazzy (J), originating from a local potato supplier were used. Samples of refined rapeseed and sunflower oil were purchased in retail trade.

2,2-diphenyl-1-picrylhydrazyl (DPPH), Folin-Ciocalteu reagent, gallic acid, $\beta$-carotene, butylated hydroxyanisole (BHA), butylated hydroxytoluene (BHT), 3-(2-pyridyl)-5,6-diphenyl-1,2,4-triazine-p,p'-disulfonic acid monosodium salt hydrate (ferrozine), linoleic acid, hexanal, nonanal, Tween 40 and sodium methanolate were purchased from Aldrich (Germany). Fatty acids methyl esters (FAME) Mix 37 certified reference material was purchased from Supelco. Potassium iodine was from Stanlab (Poland) and other reagents were from POCh (Poland).

\section{Preparation of Potato Peel Extracts}

The skin of potato tubers was removed using a vegetable peeler. The peels were dried at $60{ }^{\circ} \mathrm{C}$ in a laboratory oven and milled to a fine powder. The material was extracted three times overnight at $5{ }^{\circ} \mathrm{C}$ with one of the following solvents: $96 \%$ ethanol (E96), $80 \%$ ethanol (E80) and water (W) (Farvin Habeebullah Koduvayour et al. 2010. The extracts were lyophilized and kept at $-20{ }^{\circ} \mathrm{C}$ until further use and then dissolved in 96\% ethanol to prepare the model systems. Extracts in initial solvents, 96\% ethanol (E96), 80\% ethanol (E80) and water (W), were applied in other tests.

\section{Determination of Total Phenolic Compounds (TPCs)}

TPCs were determined with Folin-Ciocalteu reagent (Singleton and Rossi 1965). The principle of this methods involves the reaction of phenolic compounds with FolinCiocalteu reagent under basic conditions. The method measures the reducing capacity of the sample. Electron-transfer reaction occurs between reductans and Mo(VI) leading to formation of the blue complex which does not depend on the structure of phenolics (Huang et al. 2005). The primary components of the reaction mixture were as follows: 
water $(5 \mathrm{~mL})$, Folin-Ciocalteu reagent $(0.5 \mathrm{~mL})$ and diluted potato extract $(0.4 \mathrm{~mL})$. The mixture was left for $3 \mathrm{~min}$ and then $20 \%$ sodium carbonate $(1.5 \mathrm{~mL})$ was added. The volume was filled up with water to $10 \mathrm{~mL}$. After $2 \mathrm{~h}$, the absorbance was measured at the wavelength $\lambda=725 \mathrm{~nm}$ using a Genesys $6 \mathrm{UV}-\mathrm{Vis}$ (Milton Roy) spectrophotometer. For the preparation of the calibration curve, solutions of gallic acids ( 0 $500 \mathrm{mg} / \mathrm{L}$ ) were used instead of the extract. The results were reported as $\mathrm{mg}$ of gallic acid (GA)/g DW (dry weight) of the extract.

\section{Determination of DPPH Radical Scavenging Capacity}

The antiradical capacity of the potato extracts was measured using the free radical 2,2diphenyl-1-picrylhydrazyl (DPPH) with the modified method of Sánchez -Moreno et al. (1998). The method is based on reduction of radical by antioxidants present. The reduction of purple colour can be measured spectrophotometrically. Diluted potato extract $(0.5 \mathrm{~mL})$ was added to solution of DPPH $(0.036 \mathrm{~g} / 1000 \mathrm{~mL})$ in $96 \%$ ethanol ( $2 \mathrm{~mL}$ ). Immediately after mixing of the compounds, the measurements of absorbance $A$ (sample) started at $\lambda=515 \mathrm{~nm}$ on a Genesys $6 \mathrm{UV}-\mathrm{Vis}$ (Milton Roy) spectrophotometer. Decreased absorbance of the reaction mixture with extracts added proved their antiradical capacity. Absorbance of a solution without the test material was also recorded as $A$ (blank). DPPH radical scavenging capacity was calculated as the percentage inhibition:

$$
\text { Antiradical capacity }[\%]=\frac{A(\text { blank })-A(\text { sample })}{A(\text { blank })} \cdot 100 \% \text {. }
$$

The absorbance measurements were carried out for $25 \mathrm{~min}$ at 5 -min intervals. On the basis of the observed kinetics, $t=10$ min was selected to calculate the antiradical capacity.

\section{Reducing Power Assay}

The reducing power assay was based on the measurement of the antioxidant potential of compounds which act as electron donors and show ability to break the free radical chain through converting free radicals to stable products (Amarowicz et al. 2000). According to the method of Oyaizu (1986), a total of $1 \mathrm{~mL}$ of diluted potato extract was mixed with $1 \mathrm{~mL}$ of $0.2 \mathrm{M}$ phosphate buffer $(\mathrm{pH} 6.6)$ and $1 \%$ potassium ferricyanide $(1 \mathrm{~mL})$. The mixture was held at $50{ }^{\circ} \mathrm{C}(20 \mathrm{~min})$, then $10 \%$ trichloroacetic acid (TCA) was added $(1 \mathrm{~mL})$. Deionized water $(2 \mathrm{~mL})$ and $0.1 \% \mathrm{FeCl}_{3}(0.4 \mathrm{~mL})$ were pipetted into $2 \mathrm{~mL}$ of clear solution. Finally, the absorbance was measured at $\lambda=700 \mathrm{~nm}$ with the use of the Genesys 6 UV-Vis (Milton Roy) spectrophotometer. Increased absorbance of the reaction mixture with extracts added was the measure of their reducing power.

\section{Determination of Iron $\left(\mathrm{Fe}^{2+}\right)$-Chelating Activity}

The assay measures chelating potential of some agents which can bind heavy metals into complexes. The determination was carried out using the modified method described by Dinis et al. (1994). Diluted extract (1 mL) was mixed with deionized water 
$(2.6 \mathrm{~mL})$ and $4 \mathrm{mM} \mathrm{FeCl} 2(30 \mu \mathrm{l})$. After $3 \mathrm{~min}, 5 \mathrm{mM}$ ferrozine $(0.1 \mathrm{~mL})$ was pipetted into it. After $10 \mathrm{~min}$, the absorbance of mixture $A$ (sample) was read at $\lambda=562 \mathrm{~nm}$ using the Genesys $6 \mathrm{UV}-\mathrm{Vis}$ (Milton Roy) spectrophotometer. A decrease in absorbance of the samples with potato extracts added showed their iron-chelating potential. An identical procedure was applied to a solution without the test material and absorbance was read as $A$ (blank). The iron $\left(\mathrm{Fe}^{2+}\right)$-chelating activity was calculated with the use of the formula:

$$
\text { Iron-chelating activity }[\%]=\frac{A(\text { blank })-A(\text { sample })}{A(\text { blank })} \cdot 100 \% \text {. }
$$

\section{B-Carotene Bleaching Assay}

This is a spectrophotometric assay in which the decrease in absorbance is a measure of $\beta$-carotene bleaching by the oxidation products of linoleic acid. The recorded depletion is lower with higher inhibitory properties of the tested substance. The assay was conducted using the modified method of Taga et al. (1984). A mixture (1:1:1) of the following solutions was prepared: (1) $\beta$-carotene in chloroform $(1 \mathrm{mg} / 10 \mathrm{~mL}),(2)$ linoleic acid in chloroform $(0.5 \mathrm{~g} / 25 \mathrm{~mL})$ and (3) Tween 40 in chloroform $(2 \mathrm{~g} / 10 \mathrm{~mL})$. A rotary evaporator was used to remove the solvent at $40{ }^{\circ} \mathrm{C}$. Deionized water $(50 \mathrm{~mL})$ was added to the residue followed by $0.1 \mathrm{M} \mathrm{NaOH}$ solution to reach $\mathrm{pH}=8.5$. Then $1 \mathrm{~mL}$ of diluted extract and $5 \mathrm{~mL}$ of the emulsion were collected together and stored at $50{ }^{\circ} \mathrm{C}$. Finally, the absorbance values were read at $\lambda=470 \mathrm{~nm}$ using the Genesys 6 UV-Vis (Milton Roy) spectrophotometer every 20 min for $2 \mathrm{~h}$. The absorbance of a control sample (emulsion without the extracts) was also recorded. The final results were expressed as follows:

$$
\beta-\text { Carotene degradation }[\%]=\left(\frac{A_{0}-A_{120}}{A_{0}}\right) \cdot 100 \%
$$

where $A_{0}$ is the absorbance at time $=0 \mathrm{~min}, A_{120}$ is the absorbance at time $=120 \mathrm{~min}$.

\section{Determination of Fatty Acid Profile of Plant Oils}

Fatty acid methyl esters (FAME) were prepared with hexane $(1 \mathrm{~mL})$ used as solvent of the rapeseed and sunflower oils (about $0.2 \mathrm{~mL}$ ). Then $1 \mathrm{~mL}$ of $0.4 \mathrm{~N}$ sodium methylate was added (Schulte and Weber 1989). After addition of water, the upper layer was analysed with the use of an Agilent 7820A gas chromatograph equipped with a flameionization detector and a BPX-70 column (SGE, $60 \mathrm{~m} \times 0.25 \mathrm{~mm}, 0.25 \mu \mathrm{m}$ ), with oven working in a programmed mode: $140{ }^{\circ} \mathrm{C}(5 \mathrm{~min})$ raised to $240{ }^{\circ} \mathrm{C}\left(6{ }^{\circ} \mathrm{C} / \mathrm{min}\right)$. The temperatures of the injector and detector were 250 and $270{ }^{\circ} \mathrm{C}$, split ratio was 1:50 (Klensporf-Pawlik et al. 2018). Helium was the carrier gas. The basis for FAME identification was a certified standard mixture. The results were expressed as a percentage fraction of total fatty acids. 


\section{Preparation of Model Lipid Substrates}

Potato peel extracts dissolved in ethanol were added to samples of rapeseed (RO) and sunflower (SO) oil in concentrations of 200 and 500 ppm (based on the extracts' dry weight). Ethanol was removed by extended flushing with argon. Synthetic antioxidants BHA and BHT were used (200 ppm) for comparison. Samples without added antioxidants served as the controls. Ten-millilitre portions of such prepared model systems were placed in glass vials $(22 \mathrm{~mL})$, closed and stored at $50{ }^{\circ} \mathrm{C}$ under dark conditions.

\section{Peroxide Value (PV) Determination}

The measurement of peroxide value is based on the determination of iodine released from potassium iodide by 'active oxygen' present in the sample. The iodine is titrated with the standardized solution of sodium thiosulphate in the presence of starch used as a marker that all the iodine has been reacted. Transition from blue-purple to clear is an indicator of end point. The reaction proceeds in two stages (Shahidi and Zhong 2005):

1) $\mathrm{LOOH}+2 \mathrm{H}^{+}+2 \mathrm{KI} \rightarrow \mathrm{I}_{2}+\mathrm{ROH}+\mathrm{H}_{2} \mathrm{O}+2 \mathrm{~K}^{+}$

2) $\mathrm{I}_{2}+2 \mathrm{Na}_{2} \mathrm{~S}_{2} \mathrm{O}_{3} \rightarrow \mathrm{Na}_{2} \mathrm{~S}_{2} \mathrm{O}_{6}+2 \mathrm{NaI}$

Hydroperoxides were determined as PV according to the AOAC Official Method 965.33 using the iodometric method (2007). PV was measured in the samples of rapeseed oil after $0,3,6,9,15$ and 21 days of storage and in the samples of sunflower oil after $0,1,3,6$ and 9 days of storage at $50{ }^{\circ} \mathrm{C}$. Samples of oil (the amount depended on the expected results) were dissolved in $10 \mathrm{~mL}$ of chloroform. The mixture was acidified with glacial acetic $(15 \mathrm{~mL})$. In the next step, saturated solution of potassium iodine $(1 \mathrm{~mL})$ was added. The reaction mixture was vigorously shaken and placed in a dark place after $1 \mathrm{~min}$ for another $5 \mathrm{~min}$. Finally, distilled water was added $(75 \mathrm{~mL})$ and the sample was titrated with a standardized solution of sodium thiosulfate with the presence of $1 \%$ starch solution. Using the same conditions, a blank which did not contain analyte was examined. PV was calculated as follows and expressed in milliequivalents of active oxygen $\left(\mathrm{meq} \mathrm{O}_{2}\right) / \mathrm{kg}$ of oil:

$$
\mathrm{LN}=\frac{\left(V_{1}-V_{0}\right) \cdot T}{m} \cdot 1000
$$

where:

$V_{0}$-the volume of titrant used in a blank, $\mathrm{mL}$,

$V_{l}$-the volume of titrant used in a measured sample, $\mathrm{mL}$

$T$-the normality of titrant

$m$-the mass of the sample, $\mathrm{g}$

\section{Conjugated Dienes (CDs) Determination}

The method is based on the measurement of UV light absorption by conjugated fatty acids (conjugated dienes). Their formation is a result of a shift in the position of the 
double bond which accompanies production of radicals of polyunsaturated fatty acids. The presence of conjugated dienes can be measured spectrophotometrically.

Conjugated dienes were measured according to Current Protocols in Food Analytical Chemistry (2001) in rapeseed oil after 0,3,6, 9, 15 and 21 days of storage and in sunflower oil after $0,1,3,6$ and 9 days of storage of the samples at $50{ }^{\circ} \mathrm{C}$. The oils were dissolved in 2,2,4-trimethylpentane to give a final concentration of about $0.5 \mathrm{~g} / \mathrm{L}$. The absorbance was measured at wavelength $\lambda=233 \mathrm{~nm}$ with the Genesys $6 \mathrm{UV}-\mathrm{Vis}$ (Milton Roy) spectrophotometer. The results are reported as CD value which was calculated from the following formulas:

$$
\begin{aligned}
\text { CD value } & =\frac{C_{\mathrm{CD}} \cdot v \cdot 10^{3}}{W} \\
C_{\mathrm{CD}} & =\frac{A_{233}}{\varepsilon \cdot l},
\end{aligned}
$$

where

$C_{C D}$-the concentration of $\mathrm{CDs}, \mathrm{mmol} / \mathrm{mL}$

$A_{233}$-the absorbance of the measured sample

$\varepsilon$-the molar absorptivity of linoleic acid hydroperoxide $\left(2.525 \times 10^{4} \mathrm{M}^{-1} \mathrm{~cm}^{-1}\right)$

$l$-the optical path length, cm

$v$-the factor that encompasses the volume of solvent used

$10^{3}$-a unit conversion

$W$-the mass of the sample, $\mathrm{g}$

The results were expressed in $\mu \mathrm{mol} / \mathrm{g}$ of oil.

\section{Determination of Volatile Compounds}

Volatile compounds are the secondary oxidation products resulting from decomposition of hydroperoxides. They were determined after $0,9,15$ and 21 days (rapeseed oil) and $0,3,6$ and 9 days (sunflower oil) of storage at $50{ }^{\circ} \mathrm{C}$ by static headspace gas chromatography analysis (SHS-GC) using Agilent 7820A gas chromatograph coupled with Agilent 7697A headspace autosampler. The headspace fraction was injected into a CP Sil $8 \mathrm{CB}$ (Varian, $30 \mathrm{~m} \times 0.53 \mathrm{~mm} \times 1.5 \mu \mathrm{m})$, working in the mode $40{ }^{\circ} \mathrm{C}(2 \mathrm{~min})$, raised to $100{ }^{\circ} \mathrm{C}\left(8{ }^{\circ} \mathrm{C} / \mathrm{min}\right)$ and then to $200{ }^{\circ} \mathrm{C}\left(20^{\circ} \mathrm{C} / \mathrm{min}, 5.5 \mathrm{~min}\right)$ (Samotyja and Małecka 2010). The temperature of flame-ionization detector was $220^{\circ} \mathrm{C}$. Helium was the carrier gas. Standards of hexanal, nonanal and 2,4-decadienal (Aldrich, Germany) were used for identification and quantification purposes.

\section{Statistical Analysis}

All data represent mean values \pm standard deviation (SD). Statistical analysis was based on one-way analysis of variance. The post-hoc Tukey HSD procedure was applied to establish significant differences among the means $(P<0.05)$. Statistica software ver. 12.0 (StatSoft) was used for analysis. 


\section{Results and Discussion}

Both the composition and the properties of extracts from plant materials are influenced by the solvent used and by differences in the polarity of compounds present in the plants. In the present study, three solvents were used of which water allowed a higher amount of DW to be extracted, giving a yield of $21.7 \%$ for Jazzy peels and $17.8 \%$ for Gala peels. Moderate yields were obtained with $80 \%$ ethanol ( $\mathrm{J}-11.4 \%, \mathrm{G}-9.9 \%)$ and low yields with $96 \%$ ethanol (2.1\% in both cases). Solvents such as methanol, ethanol, acetone, ethyl acetate, hexane, diethyl and petroleum ethers have been used to extract phenolics from potato peels, sometimes with different proportions of water (Mohdaly et al. 2010b; Singh and Saldaña 2011). Mohdaly et al. (2010b), who carried out the extraction of cultivar Diamond peels with six organic solvents, stated that the use of either methanol or ethanol gave a higher yield. The polarity of the solvent affects the amount and rate of polyphenols extracted; for example, methanol has generally been found to be more efficient in the extraction of lower molecular weight polyphenols, while those with higher molecular weight are better extracted with aqueous acetone. Generally, ethanol is considered to be a good solvent for polyphenol extraction and is safe for human consumption (Dai and Mumper 2010).

The amount of TPC in potato peel extracts ranged from 10.1 to $40.5 \mathrm{mg} / \mathrm{g}$ of DW of crude extract and depended both on the solvent used for extraction and on the cultivar of potato (Fig. 1). Despite the fact that water was the most powerful extracting solvent, $1 \mathrm{~g}$ of water extracts had the lowest TPC. Extracts obtained with $96 \%$ ethanol exhibited the highest amount of phenolics. Within the same type of solvent, Jazzy extracts contained more phenolics than Gala extracts.

Differences resulting from the cultivar of potato as well as the extraction method have been reported in the literature (Farvin Habeebullah Koduvayour et al. 2010; Dai and Mumper 2010). The TPCs assessed in extracts obtained by Friedman et al. (2017) with the use of $80 \%$ methanol from six cultivars of potato peels ranged from 11.3 to $34.4 \mathrm{mg} / \mathrm{g}$. The levels of total phenolics in methanolic extracts of 60 cultivars of potato grown in Ireland varied considerably and ranged from 1.56 to $12.59 \mathrm{mg} / \mathrm{g}$ (Valcarcel et al. 2015). Phenolic acids (chlorogenic, caffeic, $p$-coumaric and ferulic acid), flavonoids and flavonols have been the most often investigated antioxidants of potato peels (Mohdaly et al. 2010b; Tasahil et al. 2013; Visvanathan et al. 2016).

Figure 2 shows the antioxidant properties of potato peel extracts as a function of their concentration. The results of the in vitro assays proved high antioxidant activity of extracts of cultivars Gala and Jazzy. The DPPH assay showed that potato peel extracts in $96 \%$ ethanol were better radical scavengers than in $80 \%$ ethanol, with the Jazzy extract showing better properties than the Gala extracts (Fig. 2a). Antiradical capacity increased along with the concentration, but the relation was not linear. The addition of water extracts to the DPPH solution caused analytical problems (the DPPH radical does not dissolve in water) so they were excluded from this assay.

The reducing power of the potato peel extracts increased along with an increase in their concentration (Fig. 2b). The order of the reducing power was JE96 > GE96 > JE80 $>$ GE80 $>$ JW $>$ GW and was unchanged, irrespective of the concentration of the extracts. The reducing properties of antioxidants play a crucial role in the termination reaction due to which the radical chain reaction can be interrupted (Frankel 2007). On the other hand, transition metals can react with hydroperoxides, resulting in their 


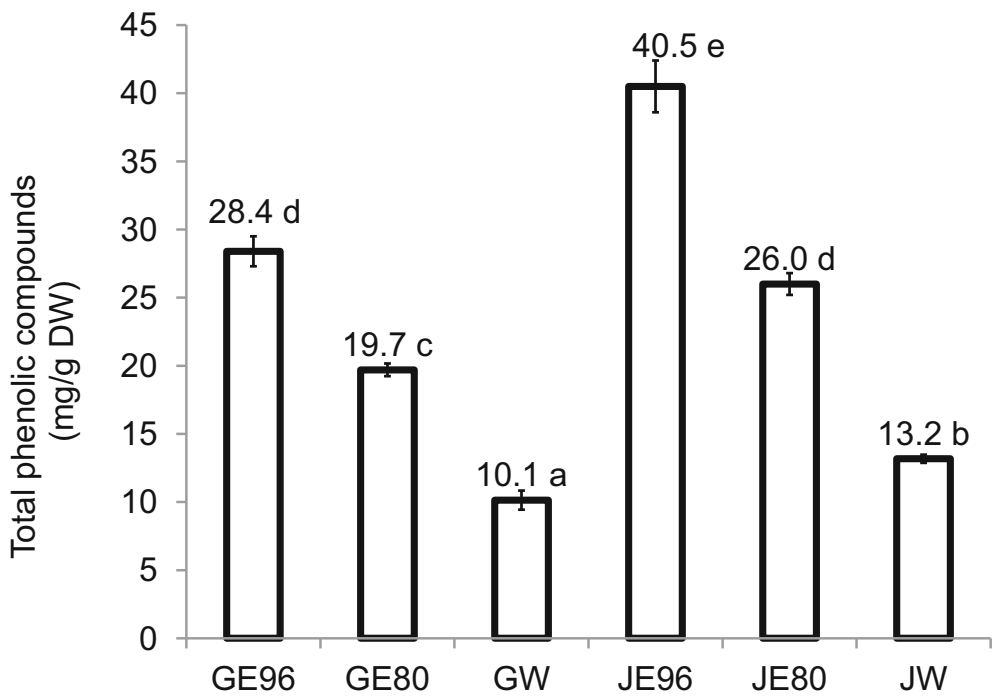

Fig. 1 Total phenolic compounds (TPCs) of extracts of potato peels of cultivars Gala and Jazzy. Data are expressed as means \pm SD $(n=3)$. GE96 Gala extract in 96\% ethanol, GE80 Gala extract in $80 \%$ ethanol, GW Gala water extract, JE96 Jazzy extract in $96 \%$ ethanol, JE80 Jazzy extract in 80\% ethanol, JW Jazzy water extract

decomposition and in generation of reactive oxygen species. This decomposition occurs via redox reactions in which both $\mathrm{Fe}^{2+}$ or $\mathrm{Fe}^{3+}$ ions can be involved, although some authors have stated that metal ions in their lower valence state are more active (Gordon 2003). These processes can explain the pro-oxidant effect of some

(a)

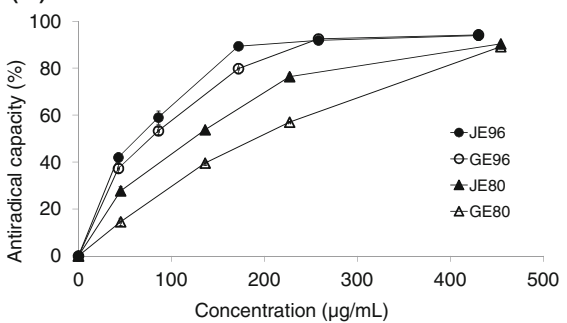

(c)

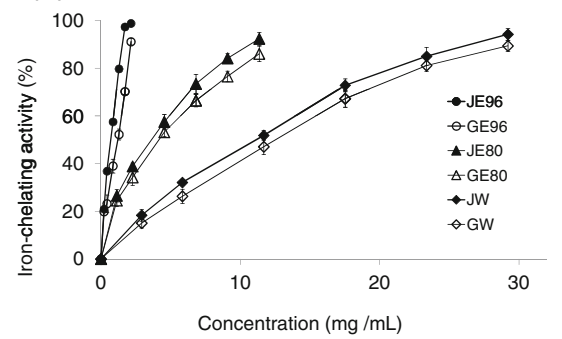

(b)

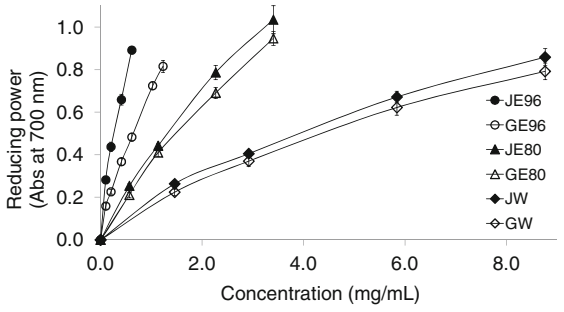

(d)

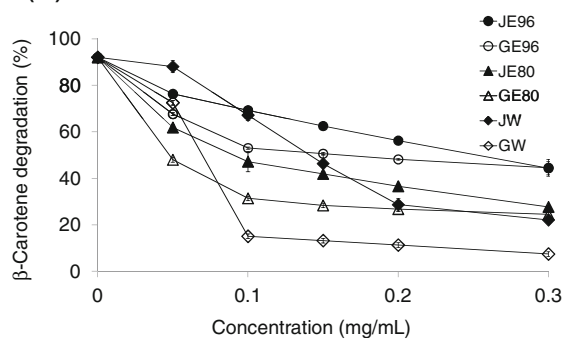

Fig. 2 Antioxidant properties of potato peel extracts. a Antiradical capacity, b reducing power, $\mathbf{c}$ ironchelating activity, $\mathbf{d}$ inhibition of $\beta$-carotene degradation. Data are expressed as means \pm SD $(n=3)$. GE96 Gala extract in $96 \%$ ethanol, GE80 Gala extract in $80 \%$ ethanol, GW Gala water extract, JE96 Jazzy extract in $96 \%$ ethanol, JE80 Jazzy extract in $80 \%$ ethanol, JW Jazzy water extract 

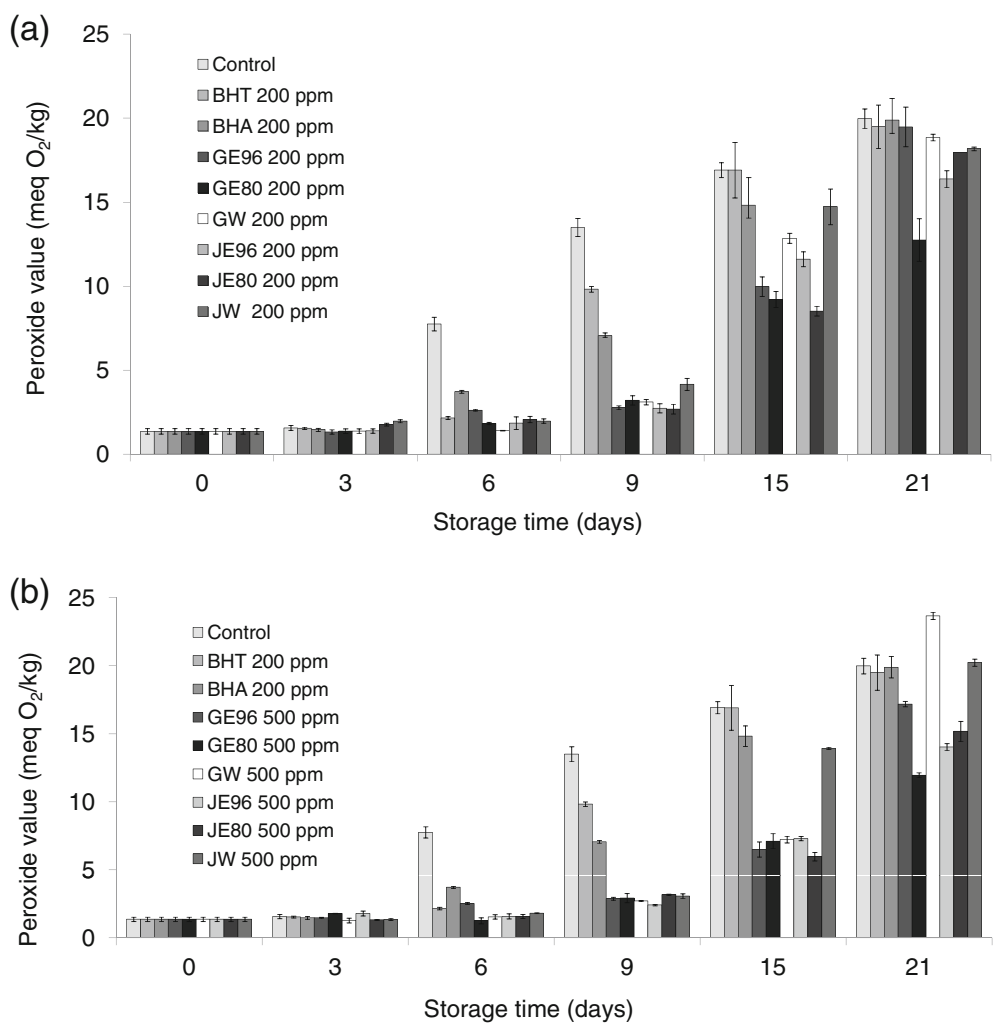

Fig. 3 a, b Effect of potato peel extracts on the formation of hydroperoxides in rapeseed oil stored at $50{ }^{\circ} \mathrm{C}$. Data are expressed as means \pm SD $(n=3)$. GE96 Gala extract in 96\% ethanol, GE80 Gala extract in $80 \%$ ethanol, GW Gala water extract, JE96 Jazzy extract in 96\% ethanol, JE80 Jazzy extract in 80\% ethanol, JW Jazzy water extract

antioxidants in foods and biological systems (Frankel 2007). In this context, besides considering the reducing power, the simultaneous role of chelating antioxidants in the binding of heavy metals into inactive compounds seems to be crucial when considering antioxidant potential. Iron $\left(\mathrm{Fe}^{2+}\right)$-chelating agents also play an important role in preventing hydroxyl radical $(\mathrm{OH})$ formation in Fenton reactions in which $\mathrm{Fe}^{2+}$ ions are involved (Frankel 2007). Farvin Habeebullah Koduvayour et al. (2010) reported a higher reducing power of ethanolic extracts, but the order was reversed when testing the iron-chelating activity of cultivar Bintje and cultivar Sava potato peel extracts. In the present study, the order of the chelating activity of potato extracts was JE96 > GE96 $>$ JE80 $>$ GE80 $>$ JW > GW (Fig. 2c) and was the same as in the reducing assay. These results may suggest the synergic effect of both mechanisms in suppressing the oxidative action of iron ions.

In the subsequent assay, $\beta$-carotene bleaching by hydroperoxide-derived free radicals resulting from linoleic acid oxidation was assessed (Fig. 2d). A higher concentration of the extracts resulted in higher inhibition of coupled oxidation but, similarly to previous tests, this dependence was not linear. Contradictory to previous tests, the concentration of extracts used in this assay strongly influenced the order of their relative effectiveness: in low concentrations the water extracts poorly inhibited $\beta$ - 
Table 1 Effect of potato peel extracts on the formation of conjugated dienes $[\mu \mathrm{mol} / \mathrm{g}]$ in rapeseed oil stored at $50{ }^{\circ} \mathrm{C}$. Data are expressed as means $\pm \mathrm{SD}(n=3)$

\begin{tabular}{|c|c|c|c|c|c|c|}
\hline \multirow[t]{2}{*}{ Sample } & \multicolumn{6}{|c|}{ Storage time (days) } \\
\hline & 0 & 3 & 6 & 9 & 15 & 21 \\
\hline Control & $10.3 \pm 0.33$ & $14.3 \pm 1.13$ & $23.6 \pm 0.32$ & $24.0 \pm 1.12$ & $24.4 \pm 1.83$ & $24.9 \pm 0.51$ \\
\hline GE96 200 ppm & $10.3 \pm 0.33$ & $12.1 \pm 0.74$ & $14.2 \pm 0.35$ & $17.1 \pm 0.98$ & $18.9 \pm 0.29$ & $19.2 \pm 0.18$ \\
\hline GE96 500 ppm & $10.3 \pm 0.33$ & $12.0 \pm 1.32$ & $16.9 \pm 0.67$ & $17.4 \pm 0.63$ & $18.4 \pm 0.50$ & $18.5 \pm 0.13$ \\
\hline GE80 200 ppm & $10.3 \pm 0.33$ & $10.5 \pm 0.32$ & $11.9 \pm 0.97$ & $13.3 \pm 0.70$ & $15.6 \pm 1.11$ & $17.0 \pm 0.44$ \\
\hline GE80 500 ppm & $10.3 \pm 0.33$ & $12.3 \pm 0.68$ & $13.8 \pm 0.38$ & $15.1 \pm 0.87$ & $16.2 \pm 0.35$ & $16.4 \pm 0.36$ \\
\hline GW 200 ppm & $10.3 \pm 0.33$ & $12.2 \pm 0.68$ & $13.7 \pm 0.71$ & $15.7 \pm 0.55$ & $17.2 \pm 0.56$ & $17.8 \pm 0.42$ \\
\hline GW 500 ppm & $10.3 \pm 0.33$ & $11.9 \pm 0.74$ & $13.2 \pm 0.74$ & $15.4 \pm 0.22$ & $17.0 \pm 0.25$ & $17.7 \pm 0.13$ \\
\hline JE96 200 ppm & $10.3 \pm 0.33$ & $11.0 \pm 1.41$ & $13.5 \pm 0.39$ & $14.3 \pm 0.83$ & $17.0 \pm 0.39$ & $19.0 \pm 0.35$ \\
\hline JE96 500 ppm & $10.3 \pm 0.33$ & $11.1 \pm 0.39$ & $13.5 \pm 0.17$ & $15.6 \pm 0.83$ & $17.4 \pm 0.68$ & $20.4 \pm 0.67$ \\
\hline JE80 200 ppm & $10.3 \pm 0.33$ & $11.4 \pm 1.15$ & $13.3 \pm 0.50$ & $16.1 \pm 0.31$ & $18.7 \pm 0.80$ & $20.7 \pm 0.46$ \\
\hline JE80 500 ppm & $10.3 \pm 0.33$ & $11.7 \pm 0.57$ & $13.6 \pm 0.73$ & $15.3 \pm 0.35$ & $17.1 \pm 0.67$ & $18.0 \pm 0.12$ \\
\hline JW 200 ppm & $10.3 \pm 0.33$ & $11.8 \pm 0.78$ & $13.5 \pm 0.76$ & $15.7 \pm 0.11$ & $19.2 \pm 0.67$ & $22.0 \pm 0.62$ \\
\hline JW 500 ppm & $10.3 \pm 0.33$ & $12.4 \pm 0.57$ & $14.1 \pm 0.35$ & $15.7 \pm 0.82$ & $18.7 \pm 0.74$ & $21.2 \pm 0.63$ \\
\hline BHT 200 ppm & $10.3 \pm 0.33$ & $11.6 \pm 0.85$ & $20.5 \pm 0.53$ & $22.5 \pm 0.98$ & $23.2 \pm 0.53$ & $23.6 \pm 0.18$ \\
\hline BHA 200 ppm & $10.3 \pm 0.33$ & $12.5 \pm 0.83$ & $13.4 \pm 0.80$ & $15.3 \pm 0.55$ & $18.1 \pm 0.59$ & $19.7 \pm 0.85$ \\
\hline
\end{tabular}

GE96 Gala extract in 96\% ethanol, GE80 Gala extract in 80\% ethanol, GW Gala water extract, JE96 Jazzy extract in 96\% ethanol, JE80 Jazzy extract in 80\% ethanol, JW Jazzy water extract

carotene degradation, whereas increased activity was observed along with an increase in their concentrations. The Gala extracts showed higher ability than the Jazzy extracts in inhibiting degradation of $\beta$-carotene, contradictory to what had been found in previous tests. The activity observed in the $\beta$-carotene bleaching assay suggests that the studied extracts can act as primary antioxidants in food lipid media, thus contributing to breaking free radical chains.

The antioxidant properties of Gala and Jazzy potato peel extracts were examined in model lipid systems. The first model's lipid medium was rapeseed oil (RO), in which the predominant fatty acids were 16:0 (4.4\%), 18:0 (1.8\%), 18:1 (61.4\%), 18:2 (20.0\%) and $18: 3$ n-3 (8.7\%). The second model system consisted of sunflower oil (SO), in which the predominant fatty acids were 16:0 (6.4\%), 18:0 (3.3\%), 18:1 (27.8\%) and 18:2 (61.0\%). In order to evaluate the extracts' antioxidant properties, their influence on the oxidative stability of lipid matrices was investigated. The course of oxidation was assessed based on measuring the formation of primary and secondary oxidation products.

The peroxide value (PV) is a measure of the concentration of hydroperoxides i.e., primary compounds that are formed during the initial stages of oxidation. The influence of potato peel extracts on the formation of hydroperoxides in rapeseed oil is presented in Fig. 3.

A continuous increase in PV during the storage period was observed in all of the samples, thus showing progressive autoxidation. Potato peel extracts of both cultivar Gala and Jazzy inhibited the formation of hydroperoxides in rapeseed oil, thus showing higher efficiency than the synthetic antioxidants BHT and BHA. Oxidative changes 

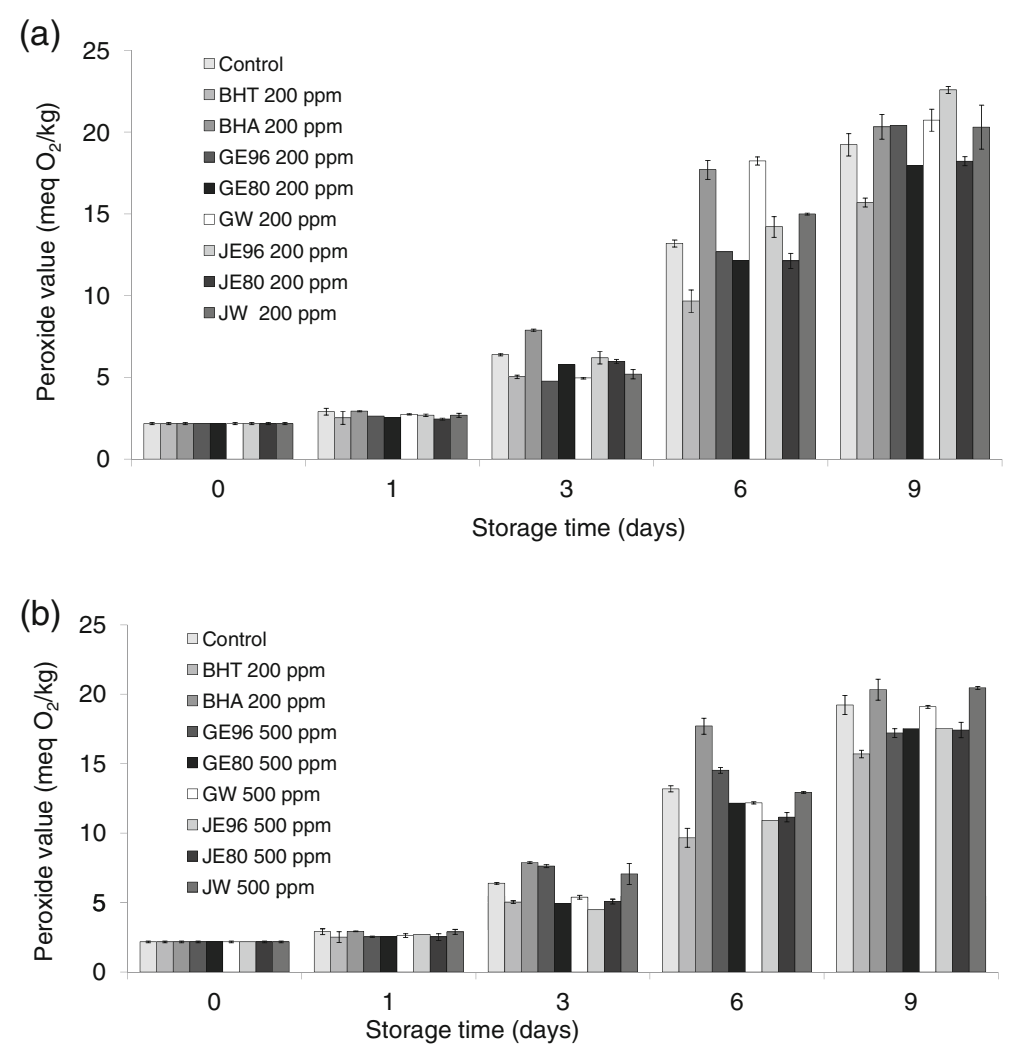

Fig. 4 a, b Effect of potato peel extracts on the formation of hydroperoxides in sunflower oil stored at $50{ }^{\circ} \mathrm{C}$. Data are expressed as means $\pm \mathrm{SD}(n=3)$. GE96 Gala extract in 96\% ethanol, GE80 Gala extract in $80 \%$ ethanol, GW Gala water extract, JE96 Jazzy extract in 96\% ethanol, JE80 Jazzy extract in 80\% ethanol, JW Jazzy water extract

were delayed to the highest degree by the extracts in $80 \%$ ethanol. The results showed that extracts used in a concentration of $500 \mathrm{ppm}$ acted for a longer period of time than those in a concentration of $200 \mathrm{ppm}$.

The potato peel extracts also slowed down the formation of conjugated diene hydroperoxides in rapeseed oil (Table 1). The levels of CDs in samples with extracts were lower than in the control sample during the entire period of the experiment. The results presented here prove the high antioxidant efficiency of potato peel extracts in delaying primary oxidative processes in rapeseed oil.

In sunflower oil, moderate activity of ethanolic extracts was observed against the formation of hydroperoxides (Fig. 4). Similar to results of $\beta$-carotene assay, increased activity of water extracts was observed along with an increase in their concentrations. The best antioxidant in sunflower oil was the synthetic compound BHT, but rather slightly different results were found in the case of CD formation (Table 2). All of the extracts used here showed high efficiency in delaying diene formation. Conjugated diene hydroperoxides are formed from polyunsaturated fatty acids, so their inhibition in sunflower oil, which contains over $60 \%$ linoleic acid, does not seem to be negligible. 
Table 2 Effect of potato peel extracts on the formation of conjugated dienes $[\mu \mathrm{mol} / \mathrm{g}]$ in sunflower oil stored at $50{ }^{\circ} \mathrm{C}$. Data are expressed as means $\pm \mathrm{SD}(n=3)$

\begin{tabular}{|c|c|c|c|c|c|}
\hline \multirow[t]{2}{*}{ Sample } & \multicolumn{5}{|c|}{ Storage time (days) } \\
\hline & 0 & 1 & 3 & 6 & 9 \\
\hline Control & $7.3 \pm 0.29$ & $13.4 \pm 0.41$ & $23.0 \pm 0.49$ & $35.4 \pm 2.18$ & $36.4 \pm 0.62$ \\
\hline GE96 200 ppm & $7.3 \pm 0.29$ & $9.2 \pm 0.41$ & $12.8 \pm 0.23$ & $16.0 \pm 0.96$ & $16.4 \pm 0.75$ \\
\hline GE96 500 ppm & $7.3 \pm 0.29$ & $8.8 \pm 0.25$ & $12.7 \pm 1.10$ & $15.7 \pm 1.14$ & $18.8 \pm 0.91$ \\
\hline GE80 200 ppm & $7.3 \pm 0.29$ & $10.8 \pm 0.94$ & $12.7 \pm 0.93$ & $15.7 \pm 0.14$ & $16.0 \pm 0.44$ \\
\hline GE80 500 ppm & $7.3 \pm 0.29$ & $11.5 \pm 0.29$ & $13.6 \pm 0.45$ & $14.5 \pm 0.22$ & $16.2 \pm 0.44$ \\
\hline GW 200 ppm & $7.3 \pm 0.29$ & $11.2 \pm 1.23$ & $12.1 \pm 0.71$ & $16.1 \pm 0.59$ & $17.7 \pm 0.48$ \\
\hline GW 500 ppm & $7.3 \pm 0.29$ & $10.9 \pm 0.18$ & $14.6 \pm 0.24$ & $16.7 \pm 0.19$ & $17.4 \pm 0.42$ \\
\hline JE96 200 ppm & $7.3 \pm 0.29$ & $9.9 \pm 0.64$ & $13.6 \pm 0.15$ & $16.3 \pm 0.24$ & $18.7 \pm 0.37$ \\
\hline JE96 500 ppm & $7.3 \pm 0.29$ & $9.7 \pm 0.13$ & $12.9 \pm 1.19$ & $17.1 \pm 0.56$ & $17.6 \pm 0.55$ \\
\hline JE80 200 ppm & $7.3 \pm 0.29$ & $8.4 \pm 0.92$ & $11.2 \pm 0.36$ & $14.6 \pm 0.26$ & $16.8 \pm 0.99$ \\
\hline JE80 500 ppm & $7.3 \pm 0.29$ & $9.3 \pm 0.11$ & $10.8 \pm 0.41$ & $15.2 \pm 0.51$ & $16.9 \pm 0.40$ \\
\hline JW 200 ppm & $7.3 \pm 0.29$ & $10.5 \pm 0.37$ & $12.5 \pm 0.27$ & $15.6 \pm 1.08$ & $18.0 \pm 0.26$ \\
\hline JW 500 ppm & $7.3 \pm 0.29$ & $11.4 \pm 0.39$ & $13.7 \pm 0.12$ & $16.7 \pm 0.60$ & $19.9 \pm 0.13$ \\
\hline BHT 200 ppm & $7.3 \pm 0.29$ & $8.0 \pm 0.78$ & $8.7 \pm 0.76$ & $13.8 \pm 0.11$ & $15.8 \pm 0.35$ \\
\hline BHA 200 ppm & $7.3 \pm 0.29$ & $11.0 \pm 0.59$ & $14.0 \pm 0.35$ & $15.5 \pm 0.82$ & $18.5 \pm 0.02$ \\
\hline
\end{tabular}

GE96 Gala extract in 96\% ethanol, GE80 Gala extract in 80\% ethanol, GW Gala water extract, JE96 Jazzy extract in 96\% ethanol, JE80 Jazzy extract in 80\% ethanol, JW Jazzy water extract

Mohdaly et al. (2010a) investigated the antioxidative potential of methanolic potato peel extracts from cultivar Diamond in both sunflower and soybean oil at concentrations ranging from 5 to $200 \mathrm{ppm}$. All of the concentrations effectively delayed hydroperoxide and diene formation, thus showing better potential than BHT at a level of $200 \mathrm{ppm}$. Their activity was lower in comparison with the action of tertbutylhydroquinone (TBHQ) in the same concentration (Mohdaly et al. 2010a). Franco et al. (2016), who studied the effect of ethanolic potato peel extracts from cultivar Agria on the oxidative stability of soybean oil, also proved their efficiency in delaying hydroperoxide and conjugated diene formation.

The efficiency of both Gala and Jazzy potato peel extracts in delaying the decomposition of primary oxidation products in plant oils was assessed using the analysis of volatile compounds formed during storage under accelerated storage conditions. The extracts were used at a concentration of $500 \mathrm{ppm}$. The most common volatile marker of oxidation is hexanal, which is a product of linoleic acid oxidative decomposition. Because of its low flavour threshold $(0.08-0.6 \mathrm{ppm})$, its presence in food is monitored and used as an index of quality and as a measure of oxidative rancidity (Gordon 2003; Azarbad and Jelen 2015). All of the applied extracts markedly inhibited hexanal formation when compared to the control (Fig. 5). As the experiment was conducted beyond acceptable values of PV of 10 meq $\mathrm{O}_{2} / \mathrm{kg}$ for refined oils (Codex Standard 2015), the results obtained here that pertain to volatile formation are promising regards using potato peel to prolong the shelf life of food. Nonanal, a cleavage product from 

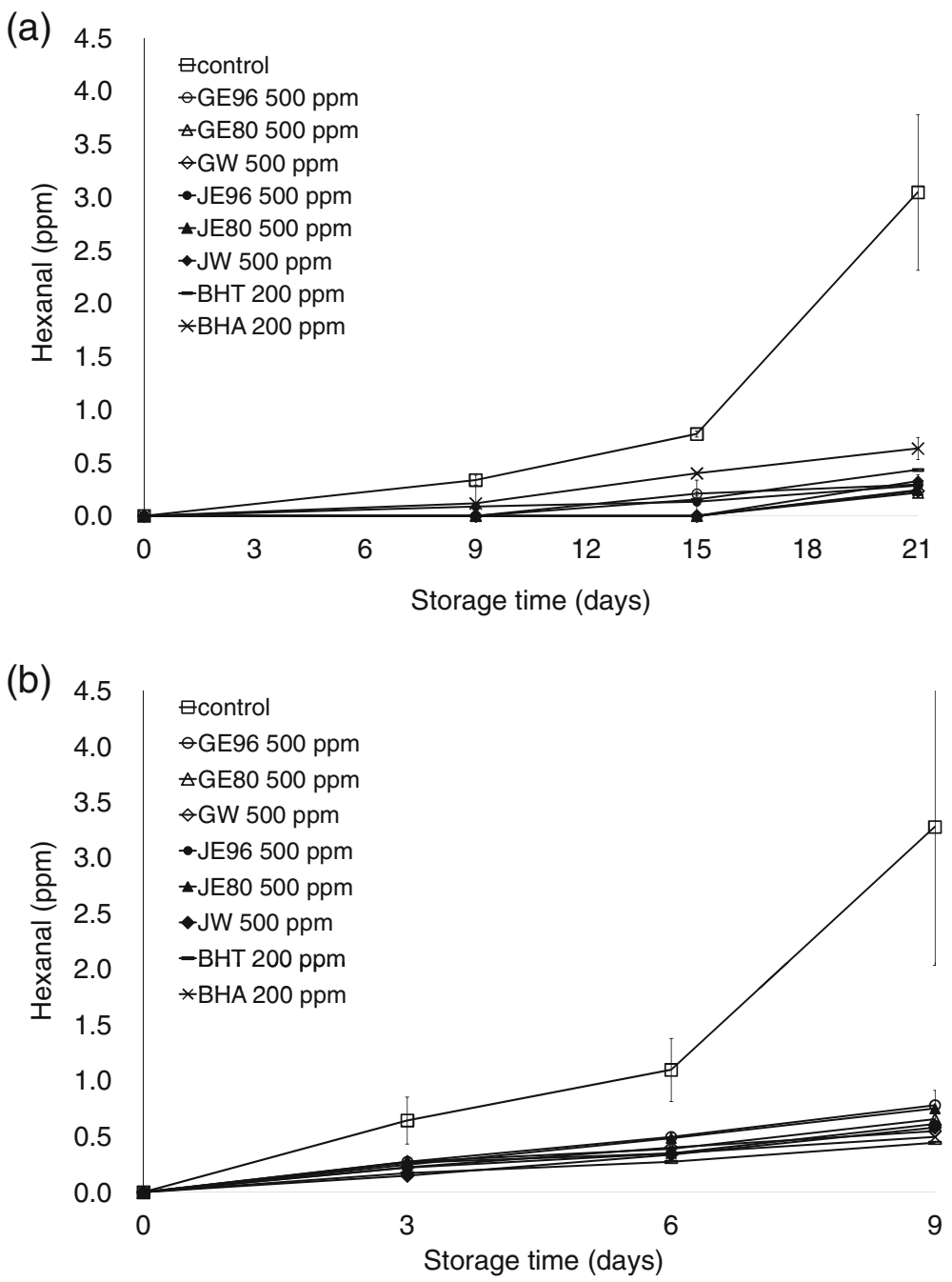

Fig. 5 Effect of potato peel extracts on hexanal formation in plant oils stored at $50{ }^{\circ} \mathrm{C}$. a Rapeseed oil, b sunflower oil. Data are expressed as means \pm SD $(n=2)$. GE96 Gala extract in 96\% ethanol, GE80 Gala extract in $80 \%$ ethanol, GW Gala water extract, JE96 Jazzy extract in 96\% ethanol, JE80 Jazzy extract in $80 \%$ ethanol, JW Jazzy water extract

oleate hydroperoxides, was found on the last day of storage only in the control samples of rapeseed $(3.0 \mathrm{ppm})$ and sunflower oil $(1.9 \mathrm{ppm})$ and in rapeseed oil stabilized by GE96 (1.1 ppm) and JE96 (1.2 ppm) (data not presented); 2,4-decadienal was not detected. The studies of other authors found good protection of soybean and sunflower oil by potato peel extracts from cultivars Diamond and Agria against secondary oxidative changes (Mohdaly et al. 2010a; Franco et al. 2016).

The plant extracts' activity in food lipids towards inhibition of primary oxidative changes does not always go in line with that of secondary oxidative changes (Samotyja and Małecka 2010). The results obtained in this study provide important information on the 
properties of both cultivar Gala and Jazzy potato peel extracts, as these are not only able to delay primary oxidative changes in food lipids but also have a positive effect on retarding oxidative rancidity which is connected with the formation of volatile aldehydes.

\section{Conclusions}

Potato peel extracts are a source of antioxidants that show high potential. The antioxidant activity observed in this study using in vitro tests was confirmed in food lipids. The results of protective action vary according to the lipid matrix, which proves the complexity of interactions between antioxidants and the lipid medium. The observed inhibitive effect against primary oxidation product formation and their degradation is a result of multiple effects.

Ethanolic extracts exhibited better antiradical, reducing and chelating activity than water extracts. They also showed higher activity in rapeseed and sunflower oil. In the inhibition of $\beta$-carotene degradation induced by linoleic acid oxidation, the extracts' relative effectiveness depended on their concentration. Further studies are necessary to explore interactions of potato peel extracts in more complex lipid matrices that constitute various food products. It is worth noticing that the activity of potato peel extracts is comparable or even better than the activity of synthetic compounds, and further studies will help contribute to the revalorization of these agri-food residues in the global food industry.

Acknowledgments I acknowledge with thanks the advice and kind help of Dr. (Mrs.) D. Klensporf-Pawlik. Also, National Science Centre (Narodowe Centrum Nauki), Poland, [grant number 2017/01/X/NZ9/00399] is greatly appreciated.

Funding Information This work was supported by the National Science Centre (Narodowe Centrum Nauki), Poland [grant number 2017/01/X/NZ9/00399].

\section{Compliance with Ethical Standards}

Conflict of Interest The author declares that there is no conflict of interest.

Open Access This article is distributed under the terms of the Creative Commons Attribution 4.0 International License (http://creativecommons.org/licenses/by/4.0/), which permits unrestricted use, distribution, and reproduction in any medium, provided you give appropriate credit to the original author(s) and the source, provide a link to the Creative Commons license, and indicate if changes were made.

\section{References}

AHDP Potatoes (2018) Potato variety database. http://varieties.ahdb.org.uk/ (accessed 1 Sept 2018)

Akyol H, Riciputi Y, Capanoglu E, Caboni MF, Verardo V (2016) Phenolic compounds in the potato and its byproducts: an overview. Int J Mol Sci. https://doi.org/10.3390/ijms17060835

Al-Weshahy A, Rao VA (2009) Isolation and characterization of functional components from peel samples of six potatoes varieties growing in Ontario. Food Res Int 42:1062-1066 
Amarowicz R, Naczk M, Shahidi F (2000) Antioxidant activity of crude tannins of canola and rapeseed hulls. J Amer Oil Chem Soc 77:957-961

AOAC Official Method 965.33 (2007) Peroxide value of oils and fats. In: official methods of analysis, 17th edn. Association of Official Analytical Chemist, Gaithersburg

Azarbad MH, Jeleń H (2015) Determination of hexanal - an indicator of lipid oxidation by static headspace gas chromatography (SHS-GC) in fat-rich food matrices. Food Anal Methods 8:1727-1733

Carocho M, Morales P, Ferreira ICFR (2018) Antioxidants: reviewing the chemistry, food applications, legislation and role as preservatives. Trends Food Sci Technol 71:107-120

Codex Standard 19-1981 (2015) Codex Standard for edible fats and oils not covered by individual standards

Current Protocols in Food Analytical Chemistry (2001) Measurement of primary lipid oxidation products. D 2.1.1-D 2.1.15. John Wiley and Sons, Hoboken

Dai J, Mumper RJ (2010) Plant Phenolics: extraction, analysis and their antioxidant and anticancer properties. Molecules 15:7313-7352

Deußer H, Guignard C, Hoffmann L, Evers D (2012) Polyphenol and glycoalkaloid contents in potato cultivars grown in Luxembourg. Food Chem 135:2814-2824

Dinis TCP, Madeira VMC, Almeida LM (1994) Action of phenolic derivates (acetoaminophen, salycilate and 5-aminosalycilate) as inhibitors of membrane lipid peroxidation and as peroxyl radical scavengers. Arch Biochem Biophys 315:161-169

European Union (2012) Charter of fundamental rights of the European Union, OJ C 326, 26.10.2012, 391407

Ezekiel R, Singh N, Sharma S, Kaur A (2013) Beneficial phytochemicals in potato - a review. Food Res Int 50:487-496

Farvin Habeebullah Koduvayour S, Nielsen NS, Jacobsen C (2010) Antioxidant activity of potato peel extracts in a fish-rapeseed oil mixture and in oil-in-water emulsions. J Am Oil Chem Soc 87:1319-1332

Franco D, Pateiro M, Rodríguez Amado I, López Pedrouso M, Zapata C, Vázquez JA, Lorenzo JM (2016) Antioxidant ability of potato (Solanum tuberosum) peel extracts to inhibit soybean oil oxidation. Eur J Lipid Sci Technol 118:1891-1902

Frankel EN (2007) Antioxidants in food and biology: facts and fiction. The Oily Press, California

Friedman M, Kozukue N, Hyun-Jeong K, Choi SH, Mizuno M (2017) Glycoalkaloid, phenolic, and flavonoid content and antioxidative activities of conventional nonorganic and organic potato peel powders from commercial gold, red, and Russet potatoes. J Food Compos Anal 62:69-75

Gebrechristos HY, Chen W (2018) Utilization of potato peel as eco-friendly products: a review. Food Sci Nutr 6:1352-1356. https://doi.org/10.1002/fsn3.691

Gordon MH (2003) Antioxidants and food stability. In: Pokorny J, Yanishlieva N, Gordon MH (eds) Antioxidants in foods: practical applications. Woodhead Publishing Ltd., CRC, Cambridge, pp 7-21

Huang D, Ou B, Prior RL (2005) The chemistry behind antioxidant capacity assays. J Agric Food Chem 53: 1841-1856

Huang W, Serra O, Dastmalchi K, Jin L, Yang L, Stark RE (2017) Comprehensive MS and solid-state NMR metabolomic profiling reveals molecular variations in native periderms from four Solanum tuberosum potato cultivars. J Agric Food Chem 65:2258-2274

Klensporf-Pawlik D, Zmudzinski W, Bąkowska A (2018) Owady jadalne źródłem bioaktywnych lipidów (in Polish, Edible insects as a source of bioactive lipids). In: Słupski J, Tarko T, Dróżdż I (eds) Żywność a składniki bioaktywne (in Polish, Food and bioactive compounds). Oddział Małopolski Polskiego Towarzystwa Technologów Żywności, Kraków, pp 154-163

Kowalska H, Czajkowska K, Cichowska J, Lenart A (2017) What's new in biopotential of fruit and vegetable by-products applied in the food processing industry. Trends Food Sci Technol 67:150-159

Mohdaly AAA, Sarhan MA, Mahmoud A, Ramadan MF, Smetanska I (2010a) Antioxidant efficacy of potato peels and sugar beet pulp extracts in vegetable oils protection. Food Chem 123:1019-1026

Mohdaly AAA, Sarhan MA, Smetanskaa I, Mahmoud A (2010b) Antioxidant properties of various solvent extracts of potato peel, sugar beet pulp and sesame cake. J Sci Food Agric 90:218-226

Oyaizu M (1986) Studies on products of browning reactions: antioxidative activities of product of browning reaction prepared from glucosamine. Jpn J Nutr 44:307-315

Özkan G, Özcan MM (2017) Antioxidant activity of some medicinal plant extracts on oxidation of olive oil. Food Measure 11:812-817

RedCorn R, Fatemi S, Engelberth AS (2018) Comparing end-use potential for industrial food-waste sources. Engineering 4:371-380

Samotyja U, Małecka M (2010) Antioxidant activity of blackcurrant seeds extract and rosemary extracts in soybean oil. Eur J Lipid Sci Technol 112:1331-1336 
Sánchez -Moreno C, Larrauri JA, Saura - Calixto F (1998) A procedure to measure the antiradical efficiency of polyphenols. J Sci Food Agric 76:270-276

Schulte E, Weber K (1989) Schnelle Herstellung der Fettsäuremethylester aus Fetten mit Trimethylsulfoniumhydroxid oder Natriummethylat. EJLST 91:181-183

Shahidi F, Zhong Y (2005) Lipid oxidation: measurement methods. In: Shahidi F (ed) Bailey's industrial oil and fat products. John Wiley \& Sons, Inc., Hoboken, pp 357-385

Sielicka M, Małecka M (2016) Enhancement of oxidative stability of flaxseed oil through flaxseed, evening primrose and black cumin cake extracts. J Food Process Preserv 41:e13070. https://doi.org/10.1111 /jfpp. 13070

Singh PP, Saldaña MDA (2011) Subcritical water extraction of phenolic compounds from potato peel. Food Res Int 44:2452-2458

Singleton VL, Rossi JA (1965) Colorimetry of total phenolics with phosphomolybdic-phosphotungstic acid reagents. Am J Enol Vitic 16:144-158

Taga MS, Miller EE, Pratt DE (1984) Chia seeds as a source of natural lipid antioxidants. JAOCS 61:928-931

Tasahil A, John JA, Al-Khalifa AS, Shahidi F (2013) Phenolic content and antioxidant activities of selected potato varieties and their processing by-products. J Funct Food 5:590-600

United Nations (2015) Transforming our world: the 2030 Agenda for sustainable development. Resolution adopted by the General Assembly on 25 Sept 2015

Valcarcel J, Reilly K, Gaffney M, O'Brien NM (2015) Antioxidant activity, total phenolic and total flavonoid content in sixty varieties of potato (Solanum tuberosum L.) grown in Ireland. Potato Res 58:221-244

Visvanathan R, Jayathilake C, Chaminda Jayawardana B, Liyanage R (2016) Health-beneficial properties of potato and compounds of interest. J Sci Food Agric 96:4850-4860

Publisher's Note Springer Nature remains neutral with regard to jurisdictional claims in published maps and institutional affiliations. 